\title{
The Characterization of Depressive Disorders in Serious Juvenile Offenders
}

\author{
Norman E. Alessi, Michael McManus, W. Lexington Grapentine and \\ Arthur Brickman
}

Mental Health Research Institute, Ann Arbor, MI 48109 (U.S.A.)

(Received 1 September, 1982)

(Accepted 31 March, 1983)

\section{Summary}

The authors systematically evaluated a selected population of juvenile offenders for the prevalence of affective disorders. Seventy-one (40 male, 31 female) serious juvenile offenders were interviewed using the Schedule for Affective Disorders and Schizophrenia (SADS). They were then diagnosed using the Research Diagnostic Criteria (RDC) and the DSM-III. The Hamilton Rating Scales (HRS), Carroll Self-Rating Scale (CSRS), and Global Rating Scale for Depression (GRS) were also obtained for each subject. Eleven (15\%) subjects were diagnosed as having an active major depressive disorder (MDDa), $6(8 \%)$ subjects were diagnosed as having a major depressive disorder in remission (MDDr), and $9(13 \%)$ as having a minor depressive disorder ( $\mathrm{mDD}$ ). The HRS, CSRS, and GRS differentiated the MDDa from the other three groups including $\mathrm{MDDr}, \mathrm{mDD}$ and all other psychiatric diagnoses. RDC subtypes of depressive disorders were identified in those juvenile offenders with active major depressive disorders (MDDa) and compared to a population of hospitalized adolescents with major depressive disorders. There were significant differences in the distribution of the subtypes identified. Secondary, gitated and endogenous subtypes occurred significantly more often. The diagnostic, prognostic and therapeutic significance of these findings are discussed.

Dr Alessi is a Research Fellow at the Mental Health Research Institute, University of Michigan. Dr. McManus is an instructor in the Child Psychiatry Service Division, Department of Psychiatry, University of Michigan Medical Center, Ann Arbor, MI. Dr. Grapentine is an Assistant Professor in the Department of Psychiatry of Brown University (Bradley Hospital). Dr. Brickman is a staff psychologist of Wyandotte General Hospital, Wyandotte, Ml.

This research was supported by grants from the State of Michigan Department of Mental Health (Grant No.80-52) and the Michigan Office of Criminal Justice.

Reprints may be requested from Norman E. Alessi, M.D., Mental Health Research Institute, University of Michigan, 205 Washtenaw Place, Ann Arbor, MI 48109, Tel. (313)763-3771. 


\section{Introduction}

Research has demonstrated that the Schedule of Affective Disorders and Schizophrenia (SADS) (Spitzer and Endicott 1978) can be used in conjunction with the RDC (Research Diagnostic Criteria) (Spitzer et al. 1977) and the DMS-III (1981) to reliably diagnose affective disorders in adolescents (Strober et al. 1981a, b; Robbins et al. 1982a). These studies have identified major depressive disorders in approximately $30 \%$ of psychiatrically hospitalized adolescents and reliably characterized major affective disorders by subtype (Strober et al. 1981b).

Two studies, with similar methodologies have investigated the population which is the focus of the current study, incarcerated juvenile delinquents (Chiles et al. 1980; Kashani et al. 1980). These studies found major depressive disorders present in $23 \%$ and $18 \%$ of subjects, respectively, indicating that these disorders were a frequent type of psychopathology among this population. In their studies, Chiles and Kashani and their coworkers examined a question of longstanding interest to investigators attempting to assess the causes of delinquency, namely the relationship between affective disturbances, mainly depression, and delinquent behavior. While Chiles et al. felt that a relationship existed between depression and "acting out behavior," a significant correlation between self-reported depression and delinquent acts was not found. Kashani et al.'s study was negative as well.

Support for the hypothesis that "acting out" or delinquent behavior is "a depressive equivalent" or expression of a "masked depression" (Kashani et al. 1980; Malmquist 1971; Toolan 1962) is found in the recent study of Kandel and Davies (1982). In a large scale epidemiological study, they found a significant positive relationship between depressive mood (self-reported) and minor delinquency. No relationship between depressive mood and major delinquent acts emerged, however. This study highlights the importance of distinguishing between different levels of delinquency and in carefully defining the affective disturbances studied.

The following study focuses on the identification of depressive disorders, major and minor, in a group of incarcerated seriously delinquent male and female adolescents, and on an examination of the relationship between diagnosed depressive disorders and several measures of severity of delinquency. In addition, comparisons are made between incarcerated delinquent and hospitalized adolescents (Strober et al. 1981b) to determine differences in the prevalence and type of depressive disorders in these two groups.

\section{Method}

Subjects in this study were delinquent adolescents housed in the training school system in the State of Michigan. Male subjects were chosen from two programs designed for the serious offender. The population of these programs was 120 . Female subjects were chosen from the state's only residential facility for delinquent girls, with a population of 60 . Subjects were selected for the study based on a set of criteria designed to identify the most seriously delinquent adolescents. These criteria 
included: (1) adjudication for violent felonies (murder, rape, armed robbery, felonious assault, arson, kidnapping); (2) adjudication for multiple non-violent felonies (greater than 3); (3) multiple placements in the training school system; and (4) assaultive in-program behavior (in which the victim required medical attention). Subjects were chosen for the study if they met two or more of these criteria. The selection criteria were used for a two-fold purpose; first, to identify the most serious offenders, and second, to insure that delinquency, which is often used non-specifically, would have adjudicated felonies as its operational definition.

All subjects were seen by two of the authors (an interviewer and an observer). The first part of the interview was semistructured and designed to provide relevant information about the subjects' school performance, social functioning and interpersonal relationships for a two-year period prior to the interview. The semistructured portion of the interview was followed by the SADS (Spitzer and Endicott 1978).

Following the completion of the interview subjects were assigned appropriate RDC and DSM-III diagnoses by the consensus of the two evaluators. For each subject, one diagnosis was designated as a primary diagnosis, indicating that based on the clinical judgment of the authors, this diagnosis was the major contributor to the pattern of psychiatric symptomatology seen at the time of evaluation. Hamilton and Global Depression Rating Scales * were completed for each subject, and each subject completed a Carroll self-rating scale of depression (Hamilton 1960; Carroll et al. 1981).

The study of Strober et al. (1981b) was selected to provide a psychiatrically hospitalized comparison population. The 40 subjects ( 12 male, 28 female, mean age 15.04) in this study were evaluated using the same methodology (interviewer and observer using SADS/RDC) as the current study.

\section{Results}

Of the 83 delinquent adolescents who met the selection criteria for the study, 71 (40 male, 31 female) were actually evaluated. Two subjects (both females) refused to participate, and ten subjects had either truanted or had been discharged prior to evaluation. The subjects ranged in age from 14 to 18 with a mean age of 16.2 years. Thirty-nine of the subjects were white ( 21 male, 18 female), 26 were black ( 19 male, 7 female), and 6 ( 2 male, 4 female) were of Hispanic or mixed racial origin. The mean socioeconomic status of the group was 4.39 using the Hollingshead-Redlich two-factor scale in which 5 is the lowest SES. As a group subjects had been in-program for an average of 9.07 months (range 1-19 months).

As a group, subjects selected for the study were seriously and repetitively delinquent. Forty-five (63\%) had committed one or more violent felonies, and 21 $(30 \%)$ three or more non-violent felonies. In addition, $25(35 \%)$ had a history of prior

\footnotetext{
* The Global Depression Rating Scale is a five-point scale (0-4) used to clinically assess the extent of depressive mood present at the time of the interview.
} 
TABLE 1

DEPRESSIVE DISORDERS BY RDC CRITERIA

\begin{tabular}{lccc}
\hline Diagnosis & No. (\%) & M & $\mathrm{F}$ \\
\hline I. Active major depressive disorder (MDDa) & $11(15 \%)$ & 4 & 7 \\
$\quad$ Unipolar major depressive disorder & 8 & 3 & 5 \\
Bipolar affective disorder with mania (Type 1) & 1 & 1 & 0 \\
Bipolar affective disorder with hypomania (Type II) & 1 & 0 & 1 \\
Schizoaffective disorder, depressed type & 1 & 0 & 1 \\
II. Major depressive disorder in remission (MDDr) & $6(8 \%)$ & 3 & 3 \\
$\quad$ Unipolar major depressive disorder & 5 & 2 & 3 \\
Bipolar affective disorder with hypomania & 1 & 1 & 0 \\
III. Minor depressive disorder (mDD) & $11(15 \%)$ & 6 & 5 \\
$\quad$ Minor & 10 & 5 & 5 \\
Chronic intermittent & 1 & 1
\end{tabular}

training school placement and $22(31 \%)$ had a history of in-program assault.

Table 1 gives the breakdown of all depressive disorders in this group by RDC criteria. The diagnoses are broken down into 3 general categories: active major depressive disorder (MDDa), major depressive disorder in remission (MDDr) and minor depressive disorder (mDD). As indicated in Table $111(15 \%)$ of subjects had active major depressive disorders (MDDa), $6(8 \%)$ had major depressive disorders in remission (MDDr) and another 11 (15\%) had minor depressive disorders (mDD). Subjects with active major depressive disorders (MDDa) received a range of diagnoses including unipolar major depressive disorder $(\mathrm{n}=8)$, bipolar affective disorders with mania $(\mathrm{n}=1)$, bipolar affective disorder with hypomania $(\mathrm{n}=1)$, and schizoaffective disorder $(n=1)$. All subjects with active major depressive disorder (MDDa) were clinically depressed at the time of evaluation.

The Hamilton Rating Scale (HRS), the Carroll Self-Rating Scale (CSRS) and the Global Rating Scale (GRS) all significantly differentiated subjects with active major depressive disorders (MDDa) from all remaining diagnostic groups (see Table 2), with the MDDa subjects scoring significantly higher on all three measures of depression. The depression rating scales, as would be expected, were most useful in differentiating active major depressive disorders (MDDa) from other diagnoses, but except in one instance, were not successful in differentiating subjects with major affective disorders in remission (MDDr) or minor depressive disorders (mDD) from non-depressed subjects. Subjects with major depressive disorders in remission (MDDr) did score significantly higher on the Global (GRS) than did subjects with minor depressive disorders (mDD) and non-depressed subjects.

Important in establishing the validity of the diagnosis of affective disorders, in subject groups such as the current one, in which there is little previous investigation, is the relationship between clinician-reported and subject (self)-reported levels of depression. In this study, highly significant correlations were found between clinician (HRS, GRS) and subject (CSRS) ratings of depression. The correlations for 
TABLE 2

HAMILTON RATING SCALE, CARROLL SELF-RATING SCALE, CLINICAL GLOBAL RATING OF DEPRESSION

Mean scores \pm standard error.

\begin{tabular}{lcccc}
\hline Rating scales & $\begin{array}{l}\text { MDDa } \\
(\mathrm{n}=11)\end{array}$ & $\begin{array}{l}\text { MDDr } \\
(\mathrm{n}=9)\end{array}$ & $\begin{array}{l}\text { mDD } \\
(\mathrm{n}=9)\end{array}$ & $\begin{array}{l}\text { All others } \\
(\mathrm{n}=42)\end{array}$ \\
\hline Hamilton Rating Scale & $14.0 \pm 2^{\mathrm{a}}$ & $7.0 \pm 1$ & $4.8 \pm 1$ & $5.4 \pm 1$ \\
Carroll Rating Scale & $22.0 \pm 3^{\mathrm{b}}$ & $13.0 \pm 2$ & $10.5 \pm 3$ & $13.0 \pm 1$ \\
Clinical Global Rating of Depression & $2.5 \pm 0.25^{\mathrm{c}}$ & $1.2 \pm 0.25^{\mathrm{d}}$ & $0.7 \pm 0.15$ & $0.5 \pm 1$ \\
\hline
\end{tabular}

$\mathrm{MDDa}=$ major depressive disorders, active; $\mathrm{MDDr}=$ major depressive disorder, remission; $\mathrm{mDD}=$ minor depressive disorder.

a ANOVA, $f=5.2371, d f=2, P=0.008$.

b ANOVA, $f=22.931, d f=2, P=0.001$.

c ANOVA, $f=33.316, d f=2, P=0.001$.

d ANOVA, $f=28.527$, $d f=3, P=0.005$.

subjects with MDDa were HRS/CSRS, $r=0.73, P=0.005$ and GRS $/$ CSRS, $r=$ $0.72, P=0.005$.

Table 3 focuses on the 11 (15\%) of subjects who had active major depressive disorders (MDDa) and further characterizes the major depressive disorders identified in these subjects by their subtype. In Table 3 these depressed incarcerated delinquent adolescents are compared with a sample of 40 hospitalized adolescents with major depressive disorders (Strober et al. 1981b). Delinquent adolescents with active major depressive disorders were significantly more likely to be assigned a

\section{TABLE 3}

THE COMPARISON OF THE INCIDENCE OF DEPRESSIVE SUBTYPES IN THIS POPULATION OF INCARCERATED JUVENILE OFFENDERS WITH A POPULATION OF HOSPITALIZED ADOLESCENTS

\begin{tabular}{|c|c|c|c|}
\hline \multirow[t]{2}{*}{ Subtype } & \multicolumn{2}{|l|}{ Incidence $(\%)$} & \multirow[t]{2}{*}{$P$ value $^{\mathrm{h}}$} \\
\hline & $\begin{array}{l}\text { Juvenile } \\
\text { offenders (MDDa) } \\
(\mathrm{n}=11)\end{array}$ & $\begin{array}{l}\text { Hospitalized } \\
\text { adolescents }^{a} \\
(n=40)\end{array}$ & \\
\hline Primary & 45 & 75 & 0.001 \\
\hline Secondary & 55 & 25 & 0.001 \\
\hline Psychotic & 0 & 13 & 0.001 \\
\hline Endogenous & 45 & 33 & 0.05 \\
\hline Incapacitated & 0 & 20 & 0.001 \\
\hline Agitated & 36 & 10 & 0.001 \\
\hline Situational & 45 & 38 & ns \\
\hline Retarded & 9 & 18 & ns \\
\hline
\end{tabular}

\footnotetext{
a Strober et al. (1981a).
}

b With Yate's Correction Factor. 
diagnosis of secondary depression than were the hospitalized adolescent subjects. Three of the delinquent subjects had combined diagnoses of alcohol and substance abuse, two had diagnoses of substance abuse and one a diagnosis of alcohol abuse which antedated the diagnosis of depression. If antisocial personality, a diagnosis usually reserved for subjects 18 or older, was included in assessing primary versus secondary depression, 8 rather than 6 of the subjects with MDDa would have been considered to have secondary depression.

The delinquent adolescents with active major depressive disorder (MDDa) were further differentiated from the group of hospitalized adolescents by their lack of psychotic symptomatology. Approximately one-half of the MDDa delinquents were endogenously depressed as compared with one-third of the hospitalized adolescents. This difference was significant $(P=0.05)$. The MDDa delinquents were also significantly more likely to be agitated than the hospitalized adolescents. Four (36\%) of the MDDa delinquents were agitated; only one was retarded. These findings indicate that there are significant differences in the way in which major depressive disorders find symptomatic expression in delinquent versus psychiatrically hospitalized adolescents.

The majority of subjects in the study, 64 (90\%), met the DSM-III criteria for conduct disorder. The DSM-III permits diagnosis of four types of conduct disorder, defined along two parameters, socialization and aggression. In Table 4, subjects with MDDa, MDD and $\mathrm{mDD}$ are presented along with subjects with no affective diagnosis based on type of conduct disorder. For statistical comparison, subjects with no affective diagnosis were compared with subjects who had MDDa $(\mathrm{n}=11)$ and subjects with any affective disorder $(n=28)$ on the presence/absence of socialization, aggression and both socialization and aggression. There were no differences between delinquents with $\operatorname{MDDa}(n=11)$ or delinquents with any affective disorder $(n=28)$ in terms of the frequency of occurrence of socialization, aggression or both socialization and aggression (Fisher exact test). In this study delinquents with affective disorders could not be distinguished from the remaining subjects by the type of their conduct disorder.

Delinquency was defined by the adjudicated felonies of each of the subjects. Adjudicated felonies were used as a means to identify the following measures of the severity of delinquency: age of first adjudicated felony, total number of adjudicated felonies and total number of violent adjudicated felonies. Neither the delinquents

\section{TABLE 4}

TYPE OF CONDUCT DISORDER FOR THE SLBJECTS WITH AFFECTIVE AND OTHER DIAGNOSES

\begin{tabular}{llllr}
\hline & $\begin{array}{l}\text { MDDa } \\
(\mathrm{n}=11)\end{array}$ & $\begin{array}{l}\text { MDDr } \\
(\mathrm{n}=6)\end{array}$ & $\begin{array}{l}\text { mDD } \\
(\mathrm{n}=11)\end{array}$ & $\begin{array}{l}\text { Others } \\
(\mathrm{n}=36)\end{array}$ \\
\hline Soc. agg. & 5 & 6 & 6 & 8 \\
Soc. nonagg. & 3 & 0 & 1 & 8 \\
Undersoc. agg. & 0 & 0 & 3 & 16 \\
Undersoc. nonagg. & 3 & 0 & 1 & 4 \\
\hline
\end{tabular}


with MDDa $(n=11)$ or with any affective disorder $(n=28)$ had significantly higher mean values for these three measures of the severity of delinquency (Fisher exact test). In our study identification of syndromally depressed delinquents in a population in which the severity of delinquency is uniformly severe does not also identify the most severely delinquent adolescents.

\section{Discussion}

Our study of incarcerated juvenile delinquents supports the findings of earlier studies of such groups (Chiles et al. 1980; Kashani et al. 1980). Compared to these studies, active unipolar depressive disorders were found less frequently. Few studies of affective disorders in adolescents have attempted to identify patients with affective disorders in remission or minor depressive disorders (Robbins et al. 1982a). Adult studies (Boothwell and Weissman 1977; Akiskal et al. 1978) indicate that these subjects are at risk for developing major depressive disorders. When these subjects with these diagnoses are included the proportion of our delinquent sample experiencing, or at risk, for major depressive disorders was $38 \%$.

Due to the presumed difficulty in diagnosing depression and especially in a sample of serious juvenile delinquents where one might expect a high degree of minimizing, denial and lying concerning symptoms, we chose a number of instruments to support our observations. Both the Hamilton Rating Scale and the Carroll Self-Rating Scale significantly differentiated subjects with active major depressive disorder, from subjects with all other psychiatric disorders. Chiles, utilizing the Beck Depression Inventory, did not demonstrate a difference between those youth diagnosed as depressed versus non-depressed (Chiles et al. 1980). In addition, there was a strong positive correlation between clinician ratings (Hamilton) and subject ratings (Carroll) of depression. These findings strongly support the validity of the SADS in diagnosing affective disorders in delinquent populations.

When the frequency of subtypes of this sample is compared to that of a sample of depressed hospitalized adolescents, a number of distinctions become apparent. First, the active depressive disorders in the juvenile delinquents are more frequently secondary. In our sample, depressive disorders appeared most frequently secondary to substance abuse or alcoholism. If age were not a consideration in the diagnosis of antisocial personality disorder, many of the major depressive disorders would have been secondary to this diagnosis. Further investigation of delinquent samples should include evaluation of family histories for the occurrence of affective disorders, alcoholism, and sociopathy to further determine if their depressive disorders represent a form of depressive spectrum disorder (Winokur 1972).

Secondly, the agitated subtype occurred significantly more frequently in the incarcerated sample. The relatively greater frequency of agitated subtype may have two possible consequences: (1) since these youths are agitated rather than withdrawn, their depression may be overlooked, and consequently not diagnosed; and (2) their agitation may contribute to their being "violence prone". Finally, endogenous depressive disorders occurred more frequently in this group than in the hospitalized 
population. Given recent data regarding the use of the Dexamethasone Suppression Test (DST) in the diagnosis of major depressive disorders in endogenously depressed adolescents, the DST would be a useful next step in the study of this population (Crumley et al. 1982, Extein et al. 1982; Robbins et al. 1982b). Further, the DST could provide an additional means to determine if affective disorders are actually depressive spectrum disorders since adults with these types of depressive disorders have a low frequency, 3-10\% of positive DSTs (Schlesser et al. 1980). Further research of this type would be likely to provide a more rational basis for selection of delinquent adolescents for specific psychopharmacological interventions.

Affective disorders in this sample of juvenile delinquents did not correlate with the parameters used to characterize their criminality. The frequency of affective disorders did not correlate with specific types of conduct disorder or with a variety of measures of adjudicated felonies. It seems unlikely that depressive disorders play a significant role in the causation of delinquent behavior in serious and repetitive delinquents. Certain depressive features such as agitation may exacerbate violent behavior in adolescents in whom a pattern of delinquency is already well established.

In conclusion, affective disorders are prevalent in seriously delinquent adolescents. There is little data which supports a specific relationship between the occurrence of depression and specific categories of either conduct disorder or serious crimes. Further studies, involving examination of family histories and evaluation of biological markers are clearly indicated.

\section{References}

Akiskal, H., Biter, A., Puzantian, V., Rosenthal, T. and Walker, P., The nosological status of neurotic depression, Arch. Gen. Psychiat., 35 (1978) 756-766.

American Psychiatric Association, The Diagnostic and Statistical Manual of Psychiatric Diagnoses, 3rd edition, 1981.

Boothwell, S. and Weissman, M., Social impairments four years after an acute depressive episode, Amer. J. Orthopsychiatr., 47 (2) (1977) $231-237$.

Carroll, B.J., Feinberg, M., Smouse, P., Rawson, S. and Greden, J., The Carroll rating scale for depression, Part 1 (Development, reliability and validity), Brit. J. Psychiat., 138 (1981) 194-200.

Chiles, J., Miller, M. and Cox, C., Depression in an adolescent delinquent population, Arch. Gen. Psychiatr., 37 (1980) 1179-1184.

Crumley, R.F., Clevenger, J., Steinfink, D. and Oldham, D., Preliminary report on the dexamethasone suppression test for psychiatrically disturbed adolescents, Amer. J. Psychiat., 139 (1982) 1062-1064.

Extein, I.R.L., Rosenberg, G., Pottash, A.L.C. and Gold, M., The Dexamethasone Suppression Test in depressed adolescents, Amer. J. Psychiat., 139 (1982) 1617-1619.

Glasser, K., Masked depression in children and adolescents, Amer. J. Psychother., 21 (1967) 565-574.

Hamilton, M., A rating scale for depression, J. Neurol. Neurosurg. Psychiat., 23 (1960) 36-62.

Kandel, D.B. and Davies, M., Epidemiology of depressive mood in adolescents, Arch. Gen. Psychiat., 39 (1982) 1205-1212.

Kashani, J., Manning, G.W., McKnew, D.H., Cytryn, L., Simonds, J. and Wooderson, P., Depression among incarcerated delinquents, Psychiat. Res., 3 (1980) 185-191.

Malmquist, C.P., Depressions in childhood and adolescents, N. Engl. J. Med., 284 (1971) 887-893, 955-961.

Robbins, D., Alessi, N., Cook, S., Poznanski, E. and Yanchyshyn, G., The use of the research diagnostic 
criteria (RDC) for depression in adolescent psychiatric inpatients, Amer. Acad. Child Psychiat., 21 (3) (1982a) 251-255.

Robbins, D.R., Alessi, N.E., Yanchyshyn, G.W. and Colfer, M.V., Preliminary report on the dexamethasone suppression test in adolescents, Amer. J. Psychiat., 139 (1982b) 942-943.

Schlesser, M.A., Winokur, G. and Sherman, B.M., Hypothalamic-pituitary-adrenal axis - Activity in depressive illness. Its relationship to classification, Arch. Gen. Psychiat., 37 (1980) 737-743.

Spitzer, R.L. and Endicott, J., The Schedule for Affective Disorders and Schizophrenics, New York State Psychiatric Institute, New York, NY, 1978.

Spitzer, R.L., Endicott, J. and Robins, E., Research Diagnostic Criteria (RDC) for a Selected Group of Functional Disorders, 3rd edition, Biometrics Research, New York State Psychiatric Institute, New York, 1977.

Strober, M., Green, J. and Cawlson, G., The reliability of psychiatric diagnosis in hospitalized adolescents, Arch. Gen. Psychiat., 38 (1981a) 141-145.

Strober, M., Green, J. and Carlson, G. Phenomenology and subtypes of major depressive disorders in adolescents, J. Affect. Dis., 3 (1981b) 281-290.

Toolan, J.D., Depression in children and adolescents, Amer. J. Orthopsychiat., 32 (1962) 404-414.

Winokur, G., Depressive spectrum disease - Description and family study, Compr. Psychiat., 13 (1972) 3-8. 